Shat, P. C. \& KING, H. K. (1959). J. gen. Microbiol. 20, 78-88

\title{
Amino Acid Requirements for Formation of the Reductive Amination System in Bacillus subtilis
}

\author{
By P. C. SHAH AND H. K. KING \\ Department of Biochemistry, The University of Liverpool
}

\begin{abstract}
SUMMARY : Bacillus subtilis, grown on nutrient broth, casein hydrolysate, or on a mixture of amino acids simulating casein hydrolysate, yielded washed suspensions with an active reductive amination system. On simple defined media the activity of the organisms was relatively low. Additions of a variety of amino acids, singly or in simple mixtures, yielded suspensions with activities up to about half of that attained with complex media. The performance of 18 amino acids in about 200 different combinations was analysed statistically; no amino acid showed marked and significant stimulation of enzyme formation. It was concluded that a high enzyme yield requires a medium with a complex amino acid relationship, and that the performance of complex media cannot be explained directly in terms of a few active components.
\end{abstract}

Knowledge of the nutritional factors required for development of specific functions in micro-organisms is very limited, despite the detailed information available concerning the growth-requirements of many species. Not infrequently simple media which will permit growth yield organisms deficient in certain enzymes (Gale, 1940; Wainwright, 1950; Billen \& Lichstein, 1950, 1951; Pinsky \& Stokes, 1952). Washed suspensions of Bacillus subtilis can synthesize a number of amino acids by 'reductive amination' (notably alanine) when incubated with the appropriate keto acid and ammonia (Fairhurst, King \& Sewell, 1956; Shah, King, Hollis \& Fairhurst, 1957). The organism grows well on simple defined media but the activity of the reductive amination system is much less than in cultures grown on nutrient broth or casein hydrolysate. Sewell \& King (1955) found that an artificial mixture of 18 amino acids yielded organisms of the same order of activity as casein hydrolysate but simultaneous omission of threonine and isoleucine decreased the activity almost to that obtained with the basal medium. The organism was therefore capable of synthesizing all the amino acids necessary for growth but apparently required an external source of certain amino acids for optimal development of this particular enzyme system. The present paper describes an attempt to define this requirement.

\section{METHODS}

Bacillus subtilis 4 (Fairhurst et al. 1956), maintained on nutrient agar slopes, was used throughout.

Amino acids. L-Isomers were used except for glycine, DL-serine, DL-threonine, DL-ornithine and DL-methionine. Purity was checked by paper chromatography. A few experiments with L-threonine and L-methionine suggested 
that the DL-mixtures could be used without risk of specific inhibitory action on growth or enzyme formation.

Media. The basal medium contained (g.); $\mathrm{KH}_{2} \mathrm{PO}_{4}, 0 \cdot 5 ; \mathrm{Na}_{2} \mathrm{HPO}_{4} \cdot 12 \mathrm{H}_{2} \mathrm{O}$, 1; $\mathrm{NaCl}, 1.25 ;\left(\mathrm{NH}_{4}\right)_{2} \mathrm{SO}_{4}, 2$; glutamic acid, 5 ; tap water to 11 .; adjusted to $\mathrm{pH} 7$ with $\mathrm{NaOH}$ and autoclaved for $15 \mathrm{~min}$. at $15 \mathrm{lb} . / \mathrm{sq}$.in. Sucrose, lactate, glycerol, or asparagine could be used as carbon sources alternative to glutamate, but the latter was preferred as it gave better and more consistent growth. Carbohydrate media were also avoided because of the risk of interaction with amino acids during autoclaving. Sucrose, too, was known to have an inhibitory action in the formation of the reductive amination system in broth media (Sewell, 1954).

Supplementary amino acids were added to the basal medium as required equivalent to $0.02 \%$ of the L-isomer. This concentration was chosen for the following reasons. (1) $0 \cdot 1 \%(\mathrm{w} / \mathrm{v})$ of casein hydrolysate added to the basal medium gave almost maximal stimulation of enzyme formation. Presumably, therefore, no individual amino acid would be required above $0.02 \%(w / v)$. (2) Experiments with leucine and methionine showed that the stimulatory action of these amino acids had already reached its maximum at $0.02 \%(\mathrm{w} / \mathrm{v})$. (3) High concentrations of the amino acids were undesirable as many of them tended to inhibit growth. (4) Lower concentrations would have led to difficulties, in some cases, through exhaustion of the amino acid before completion of the $36 \mathrm{hr}$. growth period. In a considerable number of experiments single-dimensional paper chromatograms were run at the end of the growth period to see whether any of the amino acids had been exhausted.

Acid hydrolysate of casein (Oxo Ltd., London), $0.5 \%(\mathrm{w} / \mathrm{v})$ added to basal medium where required.

Growth. The amount of organism in cultures and washed suspensions was determined turbidimetrically with the EEL photoelectric colorimeter (Evans Electroselenium Ltd.) which was calibrated by dry-weight determinations (Sewell, 1954). Results are expressed as mg. dry wt. organism/ml.

Preparation of washed suspensions. Roux bottles containing the medium under test $(150 \mathrm{ml}$.) were inoculated with $c .0 \cdot 1 \mathrm{ml}$. of a $24 \mathrm{hr}$ culture of the organism grown on basal medium. After incubating for $36 \mathrm{hr}$. at $37^{\circ}$ the organisms were centrifuged down in glass tubes $(20 \mathrm{~min}$. at $2000 \mathrm{~g}$ ), washed twice by resuspending in distilled water and centrifuging, and finally suspended in a suitable volume of buffer to give an optical density equiv. 6-8 mg. dry wt./ml. The buffer was prepared by mixing $0 \cdot 2 \mathrm{M}-\mathrm{KH}_{2} \mathrm{PO}_{4}$ and $0 \cdot 2 \mathrm{M}-\mathrm{Na}_{2} \mathrm{HPO}_{4}$ in the proportions required to give $\mathrm{pH} 7$, and diluting to $0 \cdot 1 \mathrm{M}$ total phosphate. Choice of incubation time was important since Fairhurst $t$ al. (1956) found that reductive amination activity decreased very sharply towards the end of the logarithmic phase of growth. The use of a constant incubation-time with different media giving rise to different rates of growth might therefore produce changes in enzyme activity arising solely from differences in the "physiological age' of the cultures when harvested. Ideally the growth curve of the organism should be determined for each medium used and cultures harvested at the same stage of development. This was done in a few cases but the value of the 
procedure was doubtful since the curves varied somewhat in form and it was difficult to decide the incubation times required to produce cultures of strictly comparable physiological age. Forunately, however, the 'age of culture' effect proved to be very much less marked on simple media. Both the basal medium itself and a medium containing glutamic acid, leucine, methionine and histidine were examined from this point of view and it was found

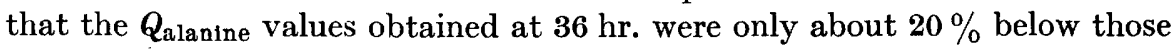
obtained after $12 \mathrm{hr}$. of incubation, when growth had only just reached the stage of appreciable turbidity. Thirty-six hr. was chosen as a standard incubation period, since in most cases this gave a reasonable yield of organisms still in the active phase of growth; maximum turbidity was usually reached only after 3-5 days on the defined media. In some of the earlier experiments (Table 1) a $\mathbf{2 4} \mathrm{hr}$. incubation period was used; with very complex amino acid mixtures it was necessary to harvest the organisms after 15-20 hr.

Measurement of enzyme activity (Fairhurst et al. 1956): buffered bacterial suspension ( $2 \mathrm{ml}$.), $0.5 \mathrm{M}$-sodium pyruvate $(1 \mathrm{ml}$.) and $0.25 \mathrm{M}$-ammonium sulphate $\left(1 \mathrm{ml}\right.$.) were incubated together $\left(4 \mathrm{hr}\right.$. at $\left.37^{\circ}\right)$. Occasionally the organisms tended to settle to the bottom of the tube and were resuspended from time to time by gentle mixing. The reaction was stopped by adding $2 \mathrm{~N}-\mathrm{H}_{2} \mathrm{SO}_{4}(2 \mathrm{ml}$.) and centrifuging down the organisms; the supernatant fluid was then stored at $0^{\circ}$, pending analysis. Blanks were run by incubating the buffered bacterial suspension and the substrates separately and mixing immediately before addition of the acid. The supernatant fluids were examined by single-dimensional paper chromatography to confirm that alanine was the only amino acid present, and the amino- $\mathrm{N}$ determined by the Van Slyke nitrous acid method after removal of excess ammonia by boiling with alkali. The activity of the system is expressed in terms of $Q_{\text {alanine }}$ after deduction of the blank, which was negligible in most cases.

In each experiment the organism was grown on basal medium for $24 \mathrm{hr}$. and this culture used to inoculate two Roux bottles containing the medium under test. The bottles were incubated and harvested as described above, a separate suspension made from each bottle, and the $Q_{\text {alanine }}$ value determined for both replicate suspensions. Results cited are means of a pair of replicates, or, in a few cases, the means of larger groups. Since (see below) the standard deviation (s.D.) for a single determination under these conditions was $9.5 \%$ it was considered desirable to repeat experiments in which the difference between the replicate pair of readings exceeded $20 \%$.

\section{RESULTS}

Variance between replicates. When replicate determinations of $Q_{\text {alanine }}$ were made on the same washed suspension the standard error (s.E.) of a single reading was $5 \cdot 1 \%$. When replicate suspensions were prepared simultaneously s.e. of a single determination of $Q_{\text {alanine was }} 9.5 \%$, or $6.6 \%$ for the mean of a pair of readings. When replicate suspensions were prepared on different days (which meant, of course, that the same inoculum could not be used for 
both) the s.E. rose to $\mathbf{1 8 . 6} \%$ for a single determination or $\mathbf{1 3 \cdot 3} \%$ for the mean of a pair of determinations. A change of at least $25 \%$ was thus required before it could be claimed that the addition of any component to the medium had influenced the activity of the enzyme system. A further complication was the occasional recording, with simple media, of $Q_{\text {alanine values approaching }}$ those normally attained only with complex media. These abnormal results were obtained on about a dozen occasions in a series of over 200 experiments, and in all cases a lower value was obtained when the experiment was repeated. As, however, these freak results were obtained in both members of the replicate pair of suspensions they could not easily be dismissed as arising from experimental error. The development of the reductive amination system may depend critically on a number of factors, some of which are not known (cf. Fairhurst et al. 1956), and the interpretation of the effects of various additions to the medium requires great caution.

The enzyme is not adaptive. Ammonium pyruvate did not enhance activity significantly when added to either nutrient broth or basal medium.

\section{Influence of amino acids on enzyme formation}

The basal medium gave suspensions with average $Q_{\text {alanine }}=8$. On complex media (nutrient broth, acid hydrolysed casein) values of the order of 50 were obtained after $15 \mathrm{hr}$. growth. $Q_{\text {alanine values only slightly below those given }}$ by casein hydrolysate were obtained when the latter was replaced by a mixture of amino acids prepared in accordance with the known composition of casein (Gordon, Semmett, Cable \& Morris, 1949), or by basal medium supplemented

\section{Table 1. Changes in reductive amination activity on adding single amino acids to basal medium}

The organism was grown for $24 \mathrm{hr}$. at $37^{\circ}$ in the basal medium + the amino acid indicated, at concentration equivalent $0.02 \%(w / v)$ of $L$-isomer. Washed suspensions were then prepared and their enzyme activity $\left(Q_{\text {alanine }}\right)$ determined.

\begin{tabular}{lclc} 
Addition & $\begin{array}{c}Q_{\text {alanine }} \\
\text { value }\end{array}$ & \multicolumn{1}{c}{ Addition } & $\begin{array}{c}Q_{\text {alanine }} \\
\text { value }\end{array}$ \\
None & $\mathbf{8}$ & Methionine & $\mathbf{2 4}$ \\
Alanine & $\mathbf{1 8}$ & Ornithine & $\mathbf{1 5}$ \\
Arginine & $\mathbf{1 9}$ & Phenylalanine & $\mathbf{1 8}$ \\
Aspartic acid & $\mathbf{1 7}$ & Proline & $\mathbf{5}$ \\
Cysteine & $\mathbf{2 1}$ & Serine & $\mathbf{2 7}$ \\
Glycine & $\mathbf{1 7}$ & Threonine & $\mathbf{2 0}$ \\
Histidine & 12 & Tryptophan & 14 \\
Isoleucine & $\mathbf{1 7}$ & Tyrosine & $\mathbf{1 1}$ \\
Leucine & 22 & Valine & $\mathbf{2 6}$ \\
Lysine & 16 & &
\end{tabular}

with alanine, arginine, aspartic acid, cysteine, glycine, histidine, isoleucine, eucine, lycine, methionine, phenylalanine, proline, serine, threonine, tryptophan, tyrosine and valine. Since the results obtained with complex media could thus be replaced by a 'complete' mixture of amino acids, the effect of adding each available amino acid in turn to the basal medium was investigated (Table 1). Many of the amino acids stimulated enzyme formation, in 
some cases up to half the value obtained with the complex media. The interpretation of the results is made difficult by the fact that many of the amino acids severely inhibited growth. The figures given in Table 1 thus represent, in some cases, cultures still in a very early stage of growth and we cannot be certain that the figures have not been influenced by 'age of culture' effects, especially as in this series of experiments the cultures were harvested after only $24 \mathrm{hr}$.

Various mixtures of those amino acids which appeared to be most stimulatory were now prepared in an attempt to achieve higher activity. Over 200 such combinations were tried, mostly comprising groups of from 3 to 7 amino acids. These results were difficult to interpret since the performance of a given amino acid was found to be much influenced by the presence of other amino acids in the medium. The results with lysine (Table 2) illustrate this. It

\section{Table 2. Effect of lysine on enzyme production}

The organism was grown at $37^{\circ}$ on basal medium (which included L-glutamic acid, $0.5 \%$ ) with addition of other amino acids, as indicated, at $0.02 \%$ of $\mathrm{L}$-isomer. After $36 \mathrm{hr}$., the amount of growth (culture density) was estimated, the organisms harvested and the enzyme activity $\left(Q_{\text {alanino }}\right)$ determined. Experiments are grouped in pairs; the second member of each pair $(b)$ being identical with the first (a), except for the addition of lysine. The difference between the pair of $Q_{a}$ andne values thus records the increase or decrease in enzyme activity following addition of lysine to the medium in question.

\begin{tabular}{|c|c|c|c|c|c|c|c|c|c|c|c|c|c|c|}
\hline Expt. & $\begin{array}{l}\text { Ghuta- } \\
\text { mic } \\
\text { acid }\end{array}$ & Leucine & $\begin{array}{c}\text { Methio- } \\
\text { nine }\end{array}$ & Glycine & Serine & $\begin{array}{c}\text { Threo- } \\
\text { nine }\end{array}$ & Alanine & $\begin{array}{l}\text { Argi- } \\
\text { nine }\end{array}$ & $\begin{array}{c}\text { Iso- } \\
\text { leucine }\end{array}$ & $\begin{array}{c}\text { Histi- } \\
\text { dine }\end{array}$ & Lysine & Qalanine & $\begin{array}{l}\text { due to } \\
\text { lysine } \\
(+ \text { or } \\
-)\end{array}$ & $\begin{array}{l}\text { Growth } \\
\text { (mg./ } \\
\text { ml. } \\
\times 10^{2} \text { ) }\end{array}$ \\
\hline $\begin{array}{l}1 a \\
1 b\end{array}$ & + & $\dot{.}$ & : & : & : & : & : & : & : & $\dot{ }$ & $\dot{t}$ & $\left.\begin{array}{r}8 \\
16\end{array}\right\}$ & +8 & $\left\{\begin{array}{l}33 \\
29\end{array}\right.$ \\
\hline $\begin{array}{l}2 a \\
2 b\end{array}$ & + & + & : & . & . & . & . & : & : & . & $\dot{t}$ & $\left.\begin{array}{l}22 \\
16\end{array}\right\}$ & -6 & $\left\{\begin{array}{l}27 \\
80\end{array}\right.$ \\
\hline $\begin{array}{l}3 a \\
3 b\end{array}$ & + & : & + & $\dot{.}$ & : & . & . & : & : & : & $\dot{+}$ & $\left.\begin{array}{l}24 \\
17\end{array}\right\}$ & -7 & $\left\{\begin{array}{l}30 \\
70\end{array}\right.$ \\
\hline $\begin{array}{l}4 a \\
4 b\end{array}$ & + & : & : & + & . & . & . & : & . & . & $\dot{+}$ & $\left.\begin{array}{l}17 \\
22\end{array}\right\}$ & +5 & $\left\{\begin{array}{r}7 \\
17\end{array}\right.$ \\
\hline $\begin{array}{l}5 a \\
5 b\end{array}$ & + & . & . & . & . & : & : & + & . & : & $\dot{t}$ & $\left.\begin{array}{l}19 \\
22\end{array}\right\}$ & +3 & $\left\{\begin{array}{r}7 \\
13\end{array}\right.$ \\
\hline $\begin{array}{l}6 a \\
6 b\end{array}$ & + & + & + & : & . & . & : & . & : & . & $\dot{t}$ & $\left.\begin{array}{l}22 \\
17\end{array}\right\}$ & -5 & $\left\{\begin{array}{l}27 \\
30\end{array}\right.$ \\
\hline $\begin{array}{l}7 a \\
7 b\end{array}$ & + & . & : & : & $\begin{array}{l}+ \\
+\end{array}$ & $\begin{array}{l}+ \\
+\end{array}$ & . & : & : & : & $\dot{t}$ & $\left.\begin{array}{l}15 \\
20\end{array}\right\}$ & +5 & $\left\{\begin{array}{r}23 \\
8\end{array}\right.$ \\
\hline $\begin{array}{l}8 a \\
8 b\end{array}$ & + & + & + & : & : & . & + & : & : & + & $\dot{+}$ & $\left.\begin{array}{l}30 \\
10\end{array}\right\}$ & -20 & $\left\{\begin{array}{l}27 \\
14\end{array}\right.$ \\
\hline $\begin{array}{l}9 a \\
9 b\end{array}$ & + & + & + & : & + & : & + & : & . & + & $\dot{+}$ & $\left.\begin{array}{l}30 \\
30\end{array}\right\}$ & 0 & $\left\{\begin{array}{l}12 \\
12\end{array}\right.$ \\
\hline $\begin{array}{l}10 a \\
10 b\end{array}$ & + & $\begin{array}{l}+ \\
+\end{array}$ & + & . & . & . & + & . & + & + & $\dot{t}$ & $\left.\begin{array}{l}17 \\
10\end{array}\right\}$ & -7 & $\left\{\begin{array}{l}10 \\
10\end{array}\right.$ \\
\hline
\end{tabular}

neither stimulated nor retarded growth when added to the basal glutamate medium (Expt. 1), but the enzyme activity was increased from 8 to 16 units. There was also an appreciable increase on adding lysine to the relatively simple media $4 a, 5 a$ and $7 a$; but it depressed activity in the combinations $2 a, 3 a$ and $6 a$. With the more complex media similar irregularity was found. Thus medium $8 a$ yielded suspensions with $Q_{a l a n t n e}=\mathbf{3 0}$ and this relatively high value was not affected by the further addition of serine $(9 a)$. But while addition of lysine had no effect on the performance of the serine-containing medium $(9 b)$ it severely depressed the formation of the enzyme in the corresponding noserine mixture $8 b$. The action of lysine cannot thus be determined by simply 
adding it to an arbitrarily-chosen medium. Quite apart from some of the factors discussed under 'variance between replicates', it can appear as either a stimulator or as an inhibitor of enzyme formation, according to the medium selected for testing purposes. We therefore tried to assess its influence by grouping the experiments in pairs as in Table 2; this shows that incorporating lysine into the 10 different media decreased enzyme formation, on an average, by 2.4 $\boldsymbol{Q}_{\text {alanine }}$ units, but the value of $\boldsymbol{P}$ (the probability of the decrease being due to chance alone) is $\mathbf{0 . 4}$, so the results may well be fortuitous and cannot serve as a basis for any claims that lysine has consistent and demonstrable effect on enzyme production.

\section{Table 3. Effect of amino acids on enzyme formation}

Pairs of media were examined, the members of each pair differing only in the presence or absence of the amino acid listed in col. 1. The number of such pairs examined in each case is listed in col. 2. Col. 3 gives the average $Q_{\text {alanine }}$ value obtained with the media lacking the amino acid cited in col. 1 ; col. 4 gives the average $Q_{\text {alanine }}$ value of the same media with addition of this amino acid. Col. 5 reports the average increase or decrease in $Q_{\text {alanino }}$ resulting from addition of the amino acid (i.e. col. 4-col. 3); col. 6 gives the standard error of this difference, and col. 7 the value of $P$, the probability that an effect as great or greater than that recorded in col. 5 should arise by chance.

\begin{tabular}{|c|c|c|c|c|c|c|}
\hline \multirow[b]{2}{*}{$\begin{array}{l}\text { Amino acid } \\
\text { (1) }\end{array}$} & \multirow[b]{2}{*}{$\begin{array}{c}\text { Expts. } \\
\text { (2) }\end{array}$} & \multicolumn{2}{|c|}{$Q_{\text {alanine }}$} & \multirow[b]{2}{*}{$\begin{array}{c}\text { Difference } \\
\text { (5) }\end{array}$} & \multirow[b]{2}{*}{$\begin{array}{l}\text { S.E. } \\
(6)\end{array}$} & \multirow[b]{2}{*}{$\begin{array}{l}P \\
(7)\end{array}$} \\
\hline & & $\begin{array}{l}\text { Without } \\
\text { (3) }\end{array}$ & $\begin{array}{c}\text { With } \\
\text { (4) }\end{array}$ & & & \\
\hline Alanine & 8 & $23 \cdot 1$ & $25 \cdot 6$ & $+2 \cdot 5$ & $4 \cdot 8$ & $0 \cdot 6$ \\
\hline Arginine & 11 & $20 \cdot 2$ & $16 \cdot 7$ & $-3 \cdot 5$ & $4 \cdot 0$ & 0.4 \\
\hline Aspartic acid & 8 & $21 \cdot 9$ & $19 \cdot 9$ & $-2 \cdot 0$ & $\mathbf{3 \cdot 5}$ & $0 \cdot 6$ \\
\hline Cysteine & 6 & $22 \cdot 6$ & 20.9 & $-2 \cdot 6$ & 4.5 & $0 \cdot 6$ \\
\hline Glycine & 10 & $21 \cdot 3$ & $14 \cdot 8$ & $-7 \cdot 5$ & $2 \cdot 6$ & 0.05 \\
\hline Histidine & 9 & $20 \cdot 1$ & $23 \cdot 6$ & $+3 \cdot 5$ & $2 \cdot 8$ & 0.4 \\
\hline Isoleucine & 19 & $17 \cdot 7$ & $20 \cdot 1$ & $+2 \cdot 4$ & $2 \cdot 5$ & 0.3 \\
\hline Leucine & 28 & $17 \cdot 3$ & $20 \cdot 3$ & $+3 \cdot 0$ & 1.5 & 0.05 \\
\hline Lysine & 10 & $20 \cdot 4$ & $18 \cdot 0$ & $-2 \cdot 4$ & $2 \cdot 6$ & 0.4 \\
\hline Methionine & 27 & $17 \cdot 3$ & $21 \cdot 3$ & $+4 \cdot 0$ & $1 \cdot 6$ & 0.02 \\
\hline Ornithine & 6 & $22 \cdot 0$ & $16 \cdot 0$ & $-6 \cdot 0$ & $3 \cdot 6$ & $0 \cdot 15$ \\
\hline Phenylalanine & 10 & $20 \cdot 8$ & $19 \cdot 9$ & -0.9 & $4 \cdot 2$ & - \\
\hline Proline & 10 & $23 \cdot 0$ & $20 \cdot 0$ & $-3 \cdot 0$ & $\mathbf{3 \cdot 5}$ & 0.4 \\
\hline Serine & 17 & $18 \cdot 1$ & $18 \cdot 8$ & +0.7 & $\mathbf{3 . 2}$ & - \\
\hline Threonine & 13 & $23 \cdot 8$ & $16 \cdot 8$ & $-7 \cdot 0$ & $3 \cdot 0$ & 0.05 \\
\hline Tryptophan & 6 & $20 \cdot 6$ & $16 \cdot 6$ & $-4 \cdot 0$ & $\mathbf{3} \cdot \mathbf{3}$ & 0.4 \\
\hline Tyrosine & 11 & 21.5 & $19 \cdot 0$ & $-2 \cdot 5$ & $\mathbf{3} \cdot \mathbf{1}$ & 0.4 \\
\hline Valine & 13 & $22 \cdot 5$ & $19 \cdot 3$ & $-3 \cdot 2$ & 0.4 & 0.4 \\
\hline
\end{tabular}

The entire series of results was treated in this way, and schedules similar to Table 2 were prepared for 18 different amino acids (excluding glutamic acid, which is present in the basal medium). The average stimulation or inhibition caused by each amino acid and the value of $\boldsymbol{P}$ are shown in Table 3. These results suggest that the high activity of complex media cannot be attributed to the action of one or a few specifically stimulatory amino acids. Most amino acids had relatively little effect on enzyme production when their average performance in a number of different combinations was assessed. Only leucine and methionine produced stimulation statistically significant at the level of $P=0.05$, and the average increase was less than $25 \%$ in both cases. Even when leucine and methionine were both added to each of 20 
different combinations of amino acids the average $Q_{\text {alanine value increased only }}$ from $15 \cdot 2$ to $20 \cdot 1 \quad(P=0 \cdot 05)$. Depression of activity (significant at $P=0 \cdot 05$ ) was shown by glycine and threonine.

The effect of threonine is particularly interesting in view of its importance in stimulating enzyme activity in complex media. Sewell \& King (1955) showed that when isoleucine and threonine were both omitted from a complete amino acid mixture, $Q_{\text {alanine }}$ fell to the value of the basal medium although omission of either amino acid separately did not cause any great decrease in activity. We have confirmed this finding. These two amino acids thus appear to play a crucial role in complex media, but in the simpler systems considered in Table 3, isoleucine showed slight stimulation whilst threonine inhibited enzyme formation. A noteworthy feature of the results shown in Table $\mathbf{3}$ is that the majority of the amino acids listed appear to inhibit enzyme production although an acceptable level of statistical significance is approached only with threonine and glycine. The high activity obtained with casein hydrolysate and the complete amino acid mixture indicate the importance of amino acids in stimulating enzyme activity and Table 1 shows that the majority of amino acids are stimulatory when added singly to the basal medium. But under the conditions of Table 3, with small groups of amino acids, it seems that interactions unfavourable to enzyme formation must occur.

It is well known that correct balance of amino acids may sometimes be required for normal growth. Gladstone (1939) found that growth of Bacillus anthracis was inhibited by either valine, leucine, or isoleucine; but growth proceeded normally if all three were present in suitable proportions. He concluded that competition was taking place between these structurally-related compounds for possession of an enzyme centre necessary for the metabolism of all three; or perhaps their entry into the cell through a specific permease mechanism is involved (Cohen \& Rickenberg, 1956). There were suggestions of such a relationship in our case: valine and isoleucine together inhibited growth less severely than did either alone. More interesting, however, were the effects of threonine and isoleucine, especially in view of the part they play in stimulating enzyme formation in complex media (Sewell \& King, 1955; see above). When added singly to the basal medium both were growth inhibitors and were still more inhibitory when added together. Isoleucine was the only amino acid (of 17 examined) which enhanced the growth inhibition caused by threonine; conversely, the inhibition caused by isoleucine was much intensified by serine and threonine. Of 16 amino acids examined, only valine and leucine effectively annulled the combined threonine + isoleucine inhibition. The amino acids were, in all cases, added to the basal media at the level of $0.02 \%$ of L-isomer.

The overall effect of different amino acids as stimulants or inhibitors of growth is shown in Table 4, constructed in the same way as Table 3. Comparison was made between pairs of media; one of each pair contained a particular group of amino acids and the other contained the same group plus the amino acid under consideration. Only leucine has an unambiguous action; it inhibits growth significantly. Nor can any correlation be established between action on 


\section{Amino acids and enzyme formation}

growth and on enzyme formation. This is important since it goes far towards excluding the possibility that the results in Table 3 arise from 'age of culture' effects due to the varying action of the amino acids on the growth of the organism.

\section{Table 4. Effect of amino acids on growth}

Columns have same significance as in Table 3, except that cols. 3-6 refer to growth obtained after $36 \mathrm{hr}$. at $37^{\circ}$.

\begin{tabular}{|c|c|c|c|c|c|c|}
\hline \multirow[b]{2}{*}{$\begin{array}{l}\text { Amino acid } \\
\text { (1) }\end{array}$} & \multirow[b]{2}{*}{$\begin{array}{c}\text { Expts. } \\
\text { (2) }\end{array}$} & \multicolumn{3}{|c|}{ Growth $\left(\mathrm{mg} \cdot / \mathrm{ml} . \times 10^{2}\right)$} & \multirow[b]{2}{*}{$\begin{array}{l}\text { S.E. } \\
(6)\end{array}$} & \multirow[b]{2}{*}{$\begin{array}{c}P \\
(7)\end{array}$} \\
\hline & & $\begin{array}{l}\text { Without } \\
\text { (3) }\end{array}$ & $\begin{array}{l}\text { With } \\
(4)\end{array}$ & $\begin{array}{c}\text { Difference } \\
(5)\end{array}$ & & \\
\hline Alanine & 7 & 20 & 17 & -3 & $4 \cdot 5$ & $0 \cdot 6$ \\
\hline Arginine & 10 & 19 & 19 & 0 & $\mathbf{5}$ & - \\
\hline Aspartic acid & 7 & 21 & 14 & -7 & $\mathbf{3}$ & 0.05 \\
\hline Cysteine & $\mathbf{5}$ & 24 & 17 & -7 & $\mathbf{3}$ & $0 \cdot 08$ \\
\hline Glycine & 9 & 21 & 20 & -1 & 5 & - \\
\hline Histidine & 9 & 31 & 21 & -10 & 7 & $0 \cdot 3$ \\
\hline Isoleucine & 19 & 19 & 24 & +5 & $\mathbf{3}$ & $0 \cdot 15$ \\
\hline Leucine & 25 & $\mathbf{5 0}$ & 27 & -23 & 6.5 & 0.001 \\
\hline Lysine & 9 & 17 & 23 & +6 & 6 & $0 \cdot 3$ \\
\hline Methionine & 23 & 33 & 28 & -5 & $8 \cdot 5$ & $0 \cdot 6$ \\
\hline Ornithine & $\mathbf{5}$ & 20 & 16 & -4 & $3 \cdot 5$ & $0 \cdot 3$ \\
\hline Phenylalanine & 9 & 20 & 16 & -4 & $2 \cdot 5$ & $0 \cdot 2$ \\
\hline Proline & 9 & 19 & 15 & -4 & $\mathbf{2 \cdot 5}$ & $0 \cdot 2$ \\
\hline Serine & 16 & 17 & 17 & 0 & 2 & - \\
\hline Threonine & 13 & 20 & 23 & +3 & 4 & $0 \cdot 4$ \\
\hline Tryptophan & 5 & 23 & 28 & +5 & $5 \cdot 5$ & $0 \cdot 4$ \\
\hline Tyrosine & 10 & 21 & 21 & o & 4 & - \\
\hline Valine & 12 & 18 & 17 & -1 & $\mathbf{3 \cdot 5}$ & - \\
\hline
\end{tabular}

\section{Influence of purine and pyrimidine bases and essential metabolites}

Although a complete mixture of amino acids produced suspensions of organisms comparable in enzyme activity with those obtained on nutrient broth or casein hydrolysate, we considered the possibility that amino acids might not be the only factors controlling enzyme production. In some cases enzyme formation will proceed only when the purine and pyrimidine constituents of the nucleic acid template are provided (Gale \& Folkes, 1955). Shortage of any essential metabolite may disturb normal metabolism, and some compounds (e.g. pyridoxal and folic acid) are known to be specially concerned in the processes which lead to protein synthesis. Addition (mg/ $100 \mathrm{ml}$. basal medium) of nicotinic acid (0.5), calcium pantothenate $(0 \cdot 1)$, riboflavin $(0 \cdot 1)$, pyridoxal hydrochloride $(0 \cdot 05)$, folic acid $(0 \cdot 005)$ and biotin $(0 \cdot 001)$ did not enhance enzyme activity appreciably. Neither did the addition of yeast extract $(0 \cdot 1 \%, \mathrm{w} / \mathrm{v})$ appreciably increase the activity of casein hydrolysate medium. Guanine inhibited growth when added to the basal medium (Table 5), but had no influence on enzyme formation. Adenine, cytosine and uracil individually stimulated growth and, to a lesser extent, enzyme formation; together they were unable, however, to annul the inhibition caused by guanine. But when guanine was added to the basal medium along with either leucine $(0.02 \%, \mathrm{w} / \mathrm{v})$ or methionine $(0.02 \%, \mathrm{w} / \mathrm{v})$ it stimulated growth but retarded enzyme formation. 
Table 5. Effect of purines and pyrimidines on growth and ezyme formation

Organisms were harvested after growth on the basal medium plus the indicated additions for $36 \mathrm{hr}$. at $37^{\circ}$. The growth (culture density at harvesting) and the enzyme activity of the harvested cells are recorded.

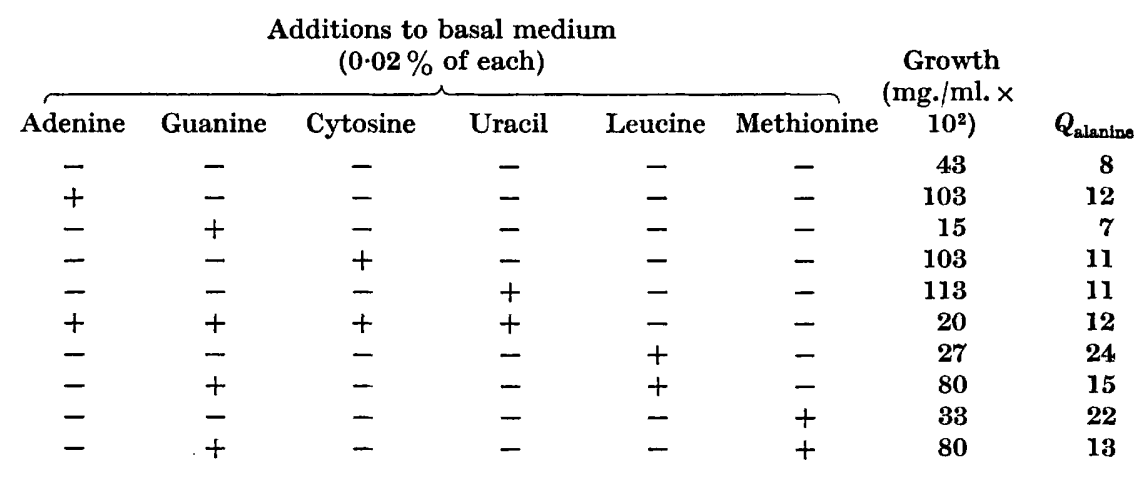

\section{DISCUSSION}

Specific amino acid requirements for the production of enzyme systems have been investigated in only a few cases. Gale (1940) reported that a strain of Streptococcus faecalis grew on a relatively simple medium but that its tyrosine decarboxylase activity was low unless casein hydrolysate was added to the medium; gelatin hydrolysate was less effective. Escherichia coli forms a number of enzymes only on relatively complex media. Optimal nitratase activity is obtained with casein hydrolysate; moderate activity was obtained on a medium containing six amino acids but the requirements were not determined precisely (Pollock \& Wainwright, 1948; Wainwright, 1950). Hydrogenase formation was stimulated by a mixture of 17 amino acids but only to $60 \%$ of the level attained with casein hydrolysate. Individually, glutamic acid, methionine, tyrosine, cysteine, serine, arginine and alanine (in descending order) showed some stimulation of enzyme formation; these seven amino acids together gave activity one-third of that obtained on casein hydrolysate (Billen \& Lichstein, 1950). With formic hydrogenlyase, glutamic acid in high concentration gave as good enzyme activity as the complex media; certain acids which had no stimulatory action per se enhanced enzyme formation when simultaneously incorporated into the medium (Billen \& Lichstein, 1951). When, however, Pinsky \& Stokes (1952) re-investigated formic hydrogenlyase formation in $E$. coli under conditions which did not permit of cell division they obtained somewhat different results. A mixture of arginine + aspartic acid + glutamic acid gave $62 \%$ of activity obtained on casein hydrolysate; and this figure was further increased by addition of cysteine, glycine, serine and threonine. They also listed six amino acids which diminished enzyme activity when added to the aspartic acid + glutamic acid + arginine mixture; and among these inhibitors was methionine, which was found to stimulate enzyme formation in Billen \& Lichstein's (1951) experiments with growing organisms. 
The present work thus falls into line with previous experience in suggesting that the effect of amino acids on enzyme formation is complex and the performance of any particular amino acid under given circumstances cannot be predicted easily. Thus there is nothing in the behaviour of threonine and isoleucine in the simpler amino acid mixtures to suggest that their simultaneous omission from the complete mixture would lead to drastic loss in activity. The development of a constitutive enzyme must depend on the presence of the appropriate genetic factors and an adequate supply of the requisite amino acids to the enzyme-synthesizing centre. Production of the enzyme will be restricted if the supply of any amino acid is limited either by the deficiency in the medium, a restricted degree of biosynthesis, blocks in the mechanism of transmission, or diversion to other metabolic pathways. Addition of an amino acid to a simple medium might accelerate enzyme production by providing a necessary component; on the other hand, it might delay it by competing for an enzyme handling a number of related amino acids (cf. Cohen \& Rickenberg, 1956); or by creating an amino acid shortage through stimulation of the synthesis of other proteins. Results such as those reported and discussed here will be difficult to interpret as long as the complex interplay of these factors remains undetermined.

We are grateful to Professor R. A. Morton, F.R.S., for his interest and encouragement, and to the Medical Research Council for a grant towards the expenses of this investigation.

\section{REFERENCES}

Billen, D. \& Lichstein, H. C. (1950). Nutritional requirements for hydrogenase production in Escherichia coli. J. Bact. 60, 311.

Billen, D. \& Lichstein, H. D. (1951). Nutritional requirements for the production of formic hydrogenlyase, formic dehydrogenase, and hydrogenase in Escherichia coli. J. Bact. 61, 515.

Cohen, G. N. \& Rickenberg, H. V. (1956). Concentration specifique reversible des amino acides chez Escherichia coli. Ann Inst. Pasteur, 91, 693.

Fairhurst, A. S., King, H. K. \& Sewell, C. E. (1956). Studies in amino acid biogenesis; the synthesis of alanine from pyruvate and ammonia. J. gen. Microbiol. 15, 106.

Gale, E. F. (1940). The production of amines by bacteria. 2. The production of tyramine by Streptococcus faecalis. Biochem. J. 34, 846.

Gale, E. F. \& Folkes, J. P. (1955). The assimilation of amino acids by bacteria. 21. The effect of nucleic acids in the development of certain enzymic activities in disrupted staphylococcal cells. Biochem. J. 59, 675 .

Gladstone, G. P. (1939). Inter-relationships between amino acids in the nutrition of B. anthracis. Brit. J. exp. Path. 20, 189.

Gordon, W. G., Semmett, W. F., Cable, R. S. \& Morris, M. (1949). The aminoacid composition of $\alpha$-casein and $\beta$-casein. J. Amer. chem. Soc. 71, 3293.

Pinsky, M. J. \& Stokes, J. L. (1952). Requirements for formic hydrogenlyase adaptation in nonproliferating suspensions of Escherichia coli. J. Bact. 64, 151.

Pollock, M. R. \& Wainwright, S. D. (1948). Relationship between nitrase and tetrathionase adaptation and cell growth. Brit. J. exp. Path. 29, 223.

Sewell, C. E. (1954). Amination of Pyruvic acid in Micro-organisms. Thesis: University of Liverpool. 
Sewell, C. E. \& KING, H. K. (1945). A threonine-isoleucine relationship in Bacillus subtilis. Biochem. J. 60, xxi.

Shah, P. C., King, H. K., Hollis, B. \& Fairhurst, A. S. (1957). Studies in aminoacid biogenesis: optical activity of amino acids formed by reductive amination in Bacillus subtilis. J. gen. Microbiol. 17, 620.

WAINwRIGHT, S. D. (1950). Formation of a bacterial adaptive enzyme system in absence of substrate: production of nitratase by B. coli without nitrate. Brit. J. exp. Path. 31, 495.

(Received 30 June 1958) 